\title{
Adding Ketamine to Xylocaine and Epinephrine in Local Infiltration for Rhinoplasty, Postoperative Analgesia and Side Effects \\ Sameh Ghareeb and Ahmed Sonbul
}

Department of Anesthesia and Surgical Intensive Care, Faculty of Medicine, Mansoura University, Mansoura, Egypt

*Corresponding author: Sameh Ghareeb, Mobile: (+20)105589289,E-Mail:sameh926@yahoo.com

\begin{abstract}
Background: Rhinoplasty is considered a surgical technique used to repair various nose deformities. This is one of the most challenging procedures in face aestheticsurgery. It is performed under general anesthetic, and often particular areas of the nose are infiltrated with $2 \%$ xylocaine and epinephrine to induce vasoconstriction, reduce surgical bleeding, and provide analgesia.

Objectives: The aim of the work was to determine the effect of combining ketamine with xylocaine and epinephrine in local infiltration.

Patients and methods: This prospective randomized study included a total of 44 cases distributed into two equal groups (22 each); the xylocaine - epinephrine (XE) group where the local infiltrationwas done by xylocaine and epinephrine. The second group xylocaine - epinephrine - ketamine (K) group includes the remaining patients in whom the local infiltration was done by xylocaine, epinephrine andketamine.Heart rate, blood pressure, visual analogue score (VAS), and morphine consumption were recorded.

Results: When group $\mathrm{K}$ was compared to group XE at 1, 2 hours post-operatively, the VAS was substantially lower.In group $\mathrm{K}$ the period for the initial request for analgesia $(3.30 \pm 1.04 \mathrm{~h})$ was longer than in group XE $(2.14 \pm 0.94 \mathrm{~h})$.A statistically significant reduction of the morphine requirement was seen in group $\mathrm{K}(7.0 \pm 3.3 \mathrm{mg})$, in comparison to group XE $(10.0 \pm 3.19 \mathrm{mg})$ during the first post-surgical 24 hours.

Conclusion: It could be concluded that adding ketamine to xylocaine-epinephrine local infiltration for rhinoplasty lowered post-operative pain ratings, delayed the initial request for analgesia, and decreased overall analgesic intake in the first 24 hours post-operatively without causing severe adverse effects.
\end{abstract}

Keywords: Rhinoplasty,xylocaine, epinephrine, ketamine,local infiltration.

\section{INTRODUCTION}

Rhinoplasty is a surgical technique that may be used to address a range of nasal deformities. It is one of the most difficult operations in the field of face cosmetic surgery ${ }^{(1)}$.

Combining general and local infiltration anesthesia prior to the initial incision lowers the need for postoperative analgesics following rhinoplasty. Few studies in the scientific literature investigate the effect of various local anesthetics and adjuvants on postoperative analgesia after rhinoplasty. Xylocaine 2\% with epinephrine is the most often used local anesthetic in rhinoplasty ${ }^{(2,3)}$.

Ketamine is a popular intravenous anesthetic in dose of $1-2 \mathrm{mg} / \mathrm{kg}$. Smaller dose can be used for sedation $^{(4)}$. Ketamine inhibits NMDA receptors, which are involved in central transmission, regulation, and sensitization of acute and chronic pain states. Additionally, research has identified NMDA receptors in the epidermis, muscles, and knee joints and shown that they are involved in the sensory transmission of noxious signals ${ }^{(5)}$.

Ketamine had been used successfully in many regional blocks topotentiate local anesthetic (LA) effect $^{(6)}$.

The aim of the current work was to determine the effect of combining ketamine with xylocaine and epinephrine in local infiltration.

\section{PATIENTS AND METHODS}

This prospective randomized study included a total of 44 cases subjected for rhinoplasty, attending at Mansoura UniversityHospitals. This study was conducted betweenDecember 2020 and June 2021.

\section{Ethical Consideration:}

This study was ethically approved by Mansoura University's Faculty of Medicine's Institutional Research Board (IRB) (Code Number: R.21.04.1308), Written informed consent of all the subjects was obtained. This work has been carried out in accordance with The Code of Ethics of the World Medical Association (Declaration of Helsinki) for studies involving humans.

Inclusion criteria: Any patient age $>21$ years, ASA I and II subjected for rhinoplasty.

Exclusion criteria: patient refusal, age $<21$, history of hypertension,coronary artery disease,psychiatric disorders,sensitivity to any of the drugs used and local skin infection.

Patients were randomly distributed into two equal groups (22 each) using closed envelope method, in accordance with the medicines used:

Xylocaine - epinephrine $(X E)$ group $(n=22)$ : patients received local infiltration composed of $6 \mathrm{ml}$ xylocaine 
$2 \%$ and $1 \mathrm{ml}$ epinephrine $1: 100000$ and $3 \mathrm{ml}$ normal saline. So, the overall volume is $10 \mathrm{ml}$.

Xylocaine - epinephrine -ketamine $(K)$ group $(n=22)$ : patients received local infiltration composed of $6 \mathrm{ml}$ xylocaine $2 \%$ and $1 \mathrm{ml}$ epinephrine 1:100000 and $3 \mathrm{ml}$ containing the determined dose of ketamine $(1 \mathrm{mg} / \mathrm{kg})$ and completed with normal saline. So, the overall volume is $10 \mathrm{ml}$.

Sequence of infiltration was Septum infiltration, Dorsum infiltration,lateral wall infiltration,columella infiltration, tip infiltration and alar base infiltration.

All blocks were made immediately after GA and about 15 minutes before to making the incision in the skin.Propofol IV (2-3 mg/kg), fentanyl $(1 \mathrm{mg} / \mathrm{kg})$ and atracurium besylate for easier intubation had been used for GA. Mechanical ventilation was used to ventilate the patient utilizing a volume control modewith an Etco2 of $30-35 \mathrm{mmHg}$, with $\mathrm{TV}$ of $6-8 \mathrm{ml} / \mathrm{kg}$, RR of $10-14$ breaths/min and I.E. ratio of $1 / 2$. Anesthesia was maintained by aMAC of $1.2 \%$ isoflurane and 60 percent air in oxygen-air mixture with atracuriumincrease up doses. Depending on body weight and intraoperative loss, IV liquids were administered intraoperatively. Following IVneostigmine $(0.05 \mathrm{mg} / \mathrm{kg})$ with atropine $(0.02 \mathrm{mg} / \mathrm{kg})$ and meeting the requirements for extubation at the conclusion of the surgery, all patients were extubated. We recorded the duration of the operation. When the systematic intraoperative blood pressure and heart rate surpassed $20 \%$ of baseline for over 5 minutes, incremental fentanyl IV doses were administered at $0.5 \mu / \mathrm{kg}$, excluding the patient.

\section{Monitoring:}

Monitoring was performed in the operation room using a 5-lead ECG, Spo2, and non-invasive MAP. Prior to anesthesia, baseline Heart Rate, Spo2, and non-invasive MAP readings were collected. Also, they were collectedafter induction of anesthesia, at the skin incision (about fifteen minutes after block) and every fifteen minutes until surgery end.

\section{Postoperative Assessment:}

When admitted to the PACU and at 1, 2, 6, 12, and 24 hours postoperatively, every vital sign and hemodynamic parameter was recorded. Additionally, at $1,2,6,12$, and 24 hours postoperatively, the 10-point VAS score was used to assess pain severity. When patients complained of pain (VAS score > 3), a bolus dose of $0.02 \mathrm{mg} / \mathrm{kg}$ IV morphine was taken every fifteen min. until the visual analogue scale score reached 3 . The duration of initial analgesic requirement was recorded. In both groups, the total amount of morphine (mg) taken within the first 24 hours postoperatively was calculated.Postoperative occurrences such as PONV had been recorded. Ramsay's modified sedation score was used to evaluate postoperative sedationwhere:

-Anxious, restless, agitated $=1$.

-Awake, butcooperative and tranquil $=2$.
-Only responsive to commands $=3$.

-Rapid reaction to a light glabellar touch or an audible stimulus $=4$.

-Response to a mild glabellar tap or a loud aural input is sluggish $=5$.

-Neither a mild glabellar touch nor a loud aural stimulation elicited a response $=6$.

\section{Sample size calculation}

The sample size was calculated using version 15.0.5 for Windows (2017) using PASSsoftware, with a published VAS score at 2 hours of the primary result of ŞANLI et al. (2016).Two groups of patients were formed: xylocaine-epinephrine (XE) group and xylocaine- epinephrine -ketamine $(\mathrm{K})$ group.The null hypothesis was defined as thestatistical absence of a significant difference in VAS scores at two hrs. after operation between the two modalities.According to ŞANLI et al. postoperative VAS score at two hours was $22.5 \pm 2.45$ for $\mathrm{XE}$ group and 17.5 in $\mathrm{K}$ group with standard deviation of 4.9.In the suggested study, 17 patients in each group is required to obtain $95 \%$ power (1- $\beta$ - or, if the null hypothesis is incorrect, the likelihood of rejecting it) when employing a two-sample unequal-variance t-test with a significance level of 5\%. According to the anticipated drop-out rate of five patients, each group recruited a total of 22 patients.

\section{Statistical analysis}

The data gathered were statistically analyzed using IBM's SPSS statistics for Windows (version 25). To establish the normality of the data distribution, the Shapiro-Wilk test was used.The mean SD of continuous data with a normal distribution was given, whereas categorical and continuous data with an atypical distribution were represented as median and interquartile range or number and percentage.For regularly distributed continuous data, the Student's t test was employed and for abnormally distributed continuous data, the Mann-Whitney test was utilized.For categorical data, the chi square test was performed using the crosstabs' function. Each test has a 95\% confidence interval. Bivariate correlations were computed when necessary, using Pearson's or Spearman's correlation coefficients, depending on the type of the data.

\section{RESULTS}

Of the 48 patients evaluated for eligibility, 44 were assigned to one of the two groups. The remaining 4 were excluded [4 met exclusion criteria] [Figure 1].

Demographic parameters, BMI, ASA classification, and surgery duration were insignificantly different between both groups(table1). There were no statistically significant changes in hemodynamic parameters between the intraoperative and postoperative periods (HR and MAP). (Figures: 2, 3). 


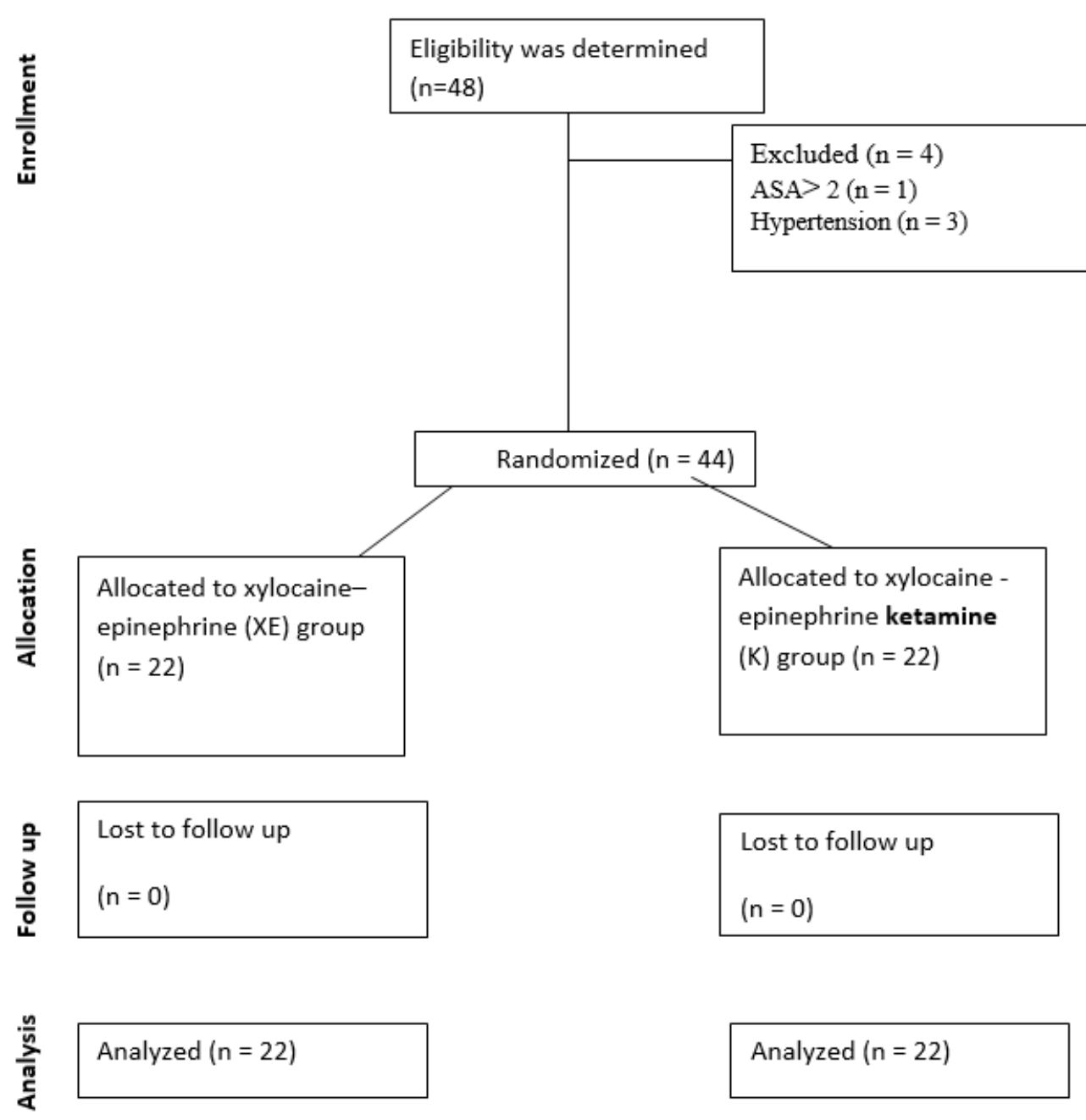

Figure [1]: Consort chart follow up

Table (1): comparison of demographic characteristics of the studied groups

\begin{tabular}{|c|c|c|c|}
\hline & $\begin{array}{l}\text { Group XE } \\
\mathrm{N}=22(\%)\end{array}$ & $\begin{array}{l}\text { Group K } \\
\mathbf{N}=22(\%)\end{array}$ & test of significance \\
\hline $\begin{array}{l}\text { Age/years } \\
\text { mean } \pm \text { SD }\end{array}$ & $29.55 \pm 4.21$ & $28.64 \pm 4.18$ & $\begin{array}{l}t=0.719 \\
p=0.476\end{array}$ \\
\hline $\begin{array}{l}\text { Sex } \\
\text { Male } \\
\text { Female }\end{array}$ & $\begin{array}{c}7(31.8 \%) \\
15(68.2 \%)\end{array}$ & $\begin{array}{c}8(36.4 \%) \\
14(63.6 \%)\end{array}$ & $\begin{aligned} \chi^{2} & =0.101 \\
p & =0.750\end{aligned}$ \\
\hline $\begin{array}{l}\text { ASA } \\
1 \\
2\end{array}$ & $\begin{array}{c}19(86.4 \%) \\
3(13.6 \%)\end{array}$ & $\begin{array}{c}20(90.9 \%) \\
2(9.1 \%)\end{array}$ & $\begin{array}{c}\text { FET } \\
p=1.0\end{array}$ \\
\hline $\begin{array}{l}\text { Duration of surgery /minutes } \\
\text { mean } \pm \text { SD }\end{array}$ & $131.18 \pm 6.78$ & $127.55 \pm 6.75$ & $\begin{array}{c}t=1.78 \\
p=0.082\end{array}$ \\
\hline $\begin{array}{l}\mathrm{BMI}(\mathrm{Kg} / \mathrm{m} 2) \\
\text { mean } \pm \mathrm{SD}\end{array}$ & $23.73 \pm 2.43$ & $23.91 \pm 3.07$ & $\begin{array}{l}\mathrm{t}=0.218 \\
\mathrm{p}=0.829\end{array}$ \\
\hline
\end{tabular}




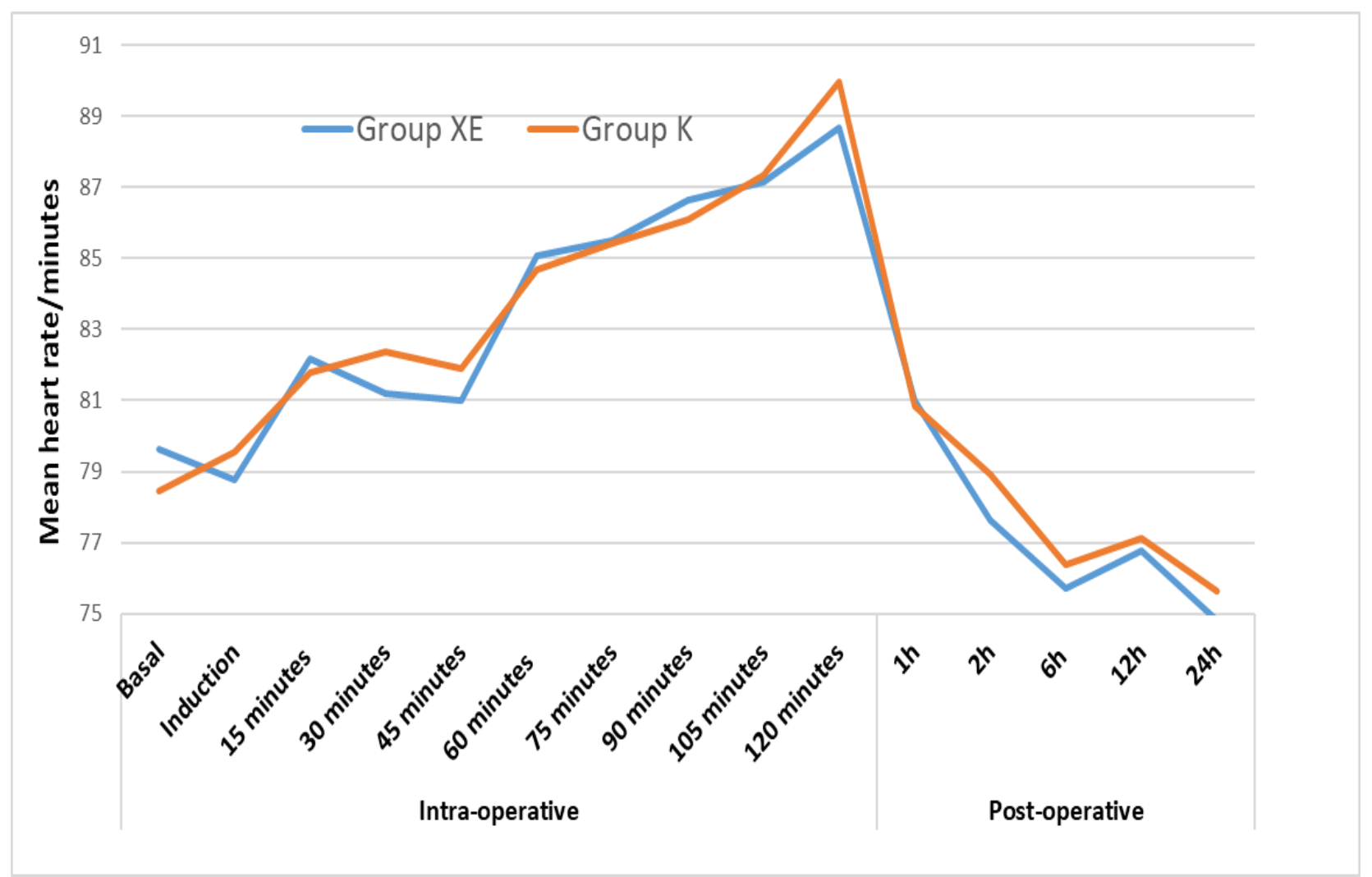

Figure (2): comparison of mean HR between studied groups intraoperatively and postoperatively.

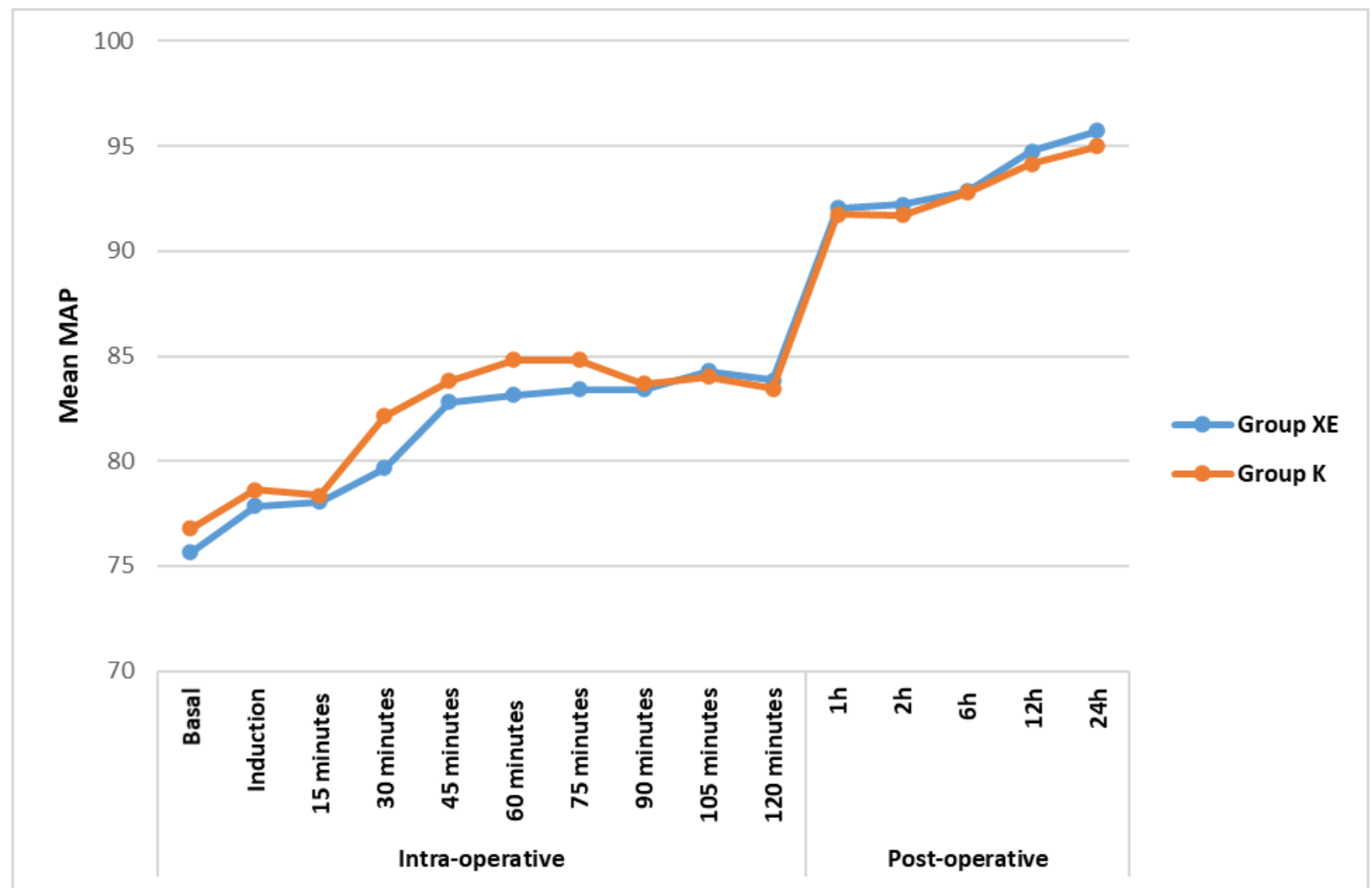

Figure (3): comparison of MAP between studied groups intraoperatively and postoperatively.

The Ramsay sedation score did not vary substantially between the two groups, while the VAS was substantially lower in group $\mathrm{K}$ at 1, 2 hours postoperatively (Figure 4). 


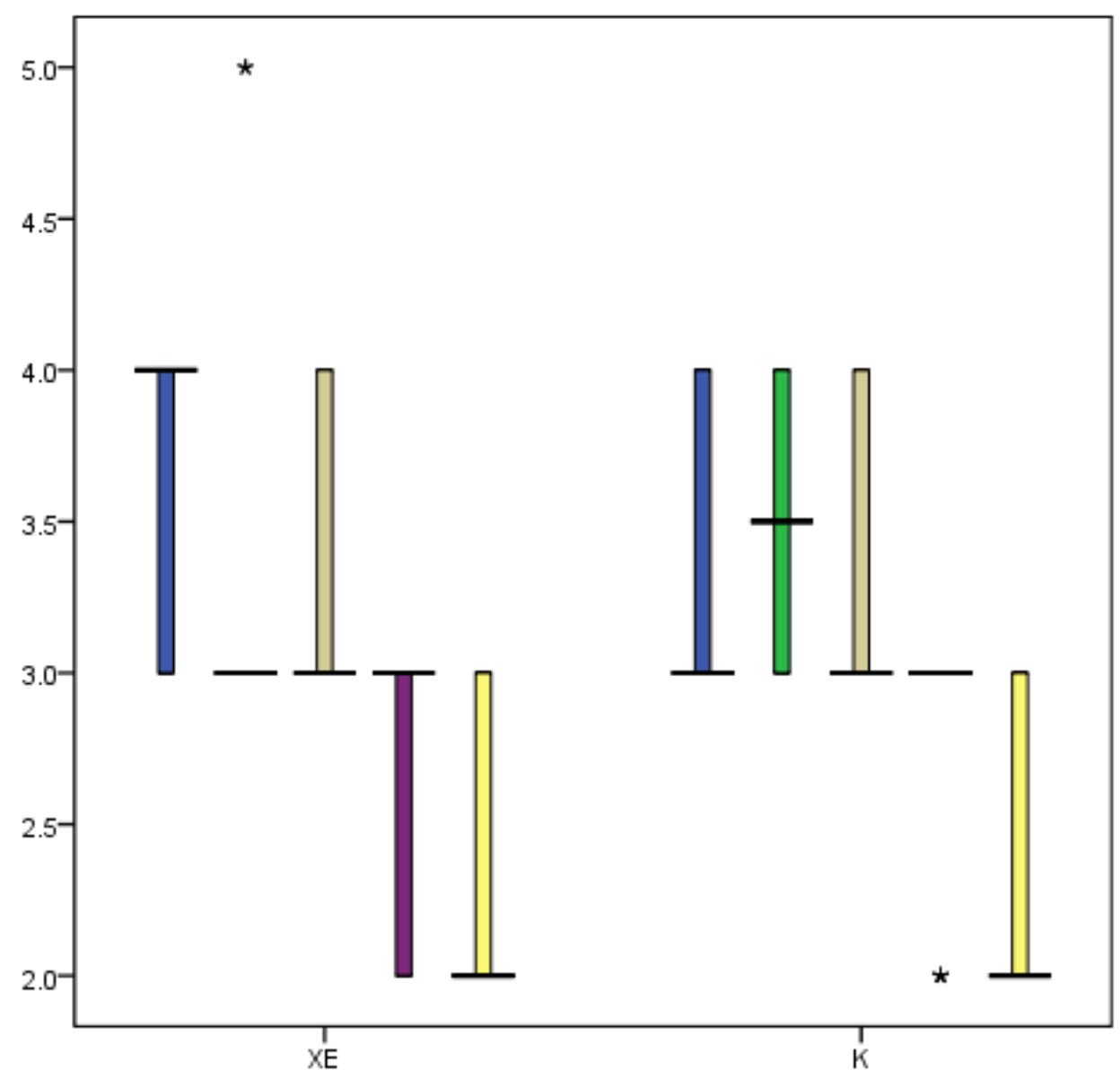

Figure (4): Comparison of VAS score during post-operative follow up between studied groups (* statistically significant)

The initial analgesic request time in group $\mathrm{K}(3.30 \pm 1.04 \mathrm{~h})$ was longer than in group XE $(2.14 \pm 0.94 \mathrm{~h})$.In the first 24-hours after the surgery, a statistically significant reduction intotal postoperative morphineadministrationwas seen in group $\mathrm{K}(7.0 \pm 3.3 \mathrm{mg})$ when compared to group XE $(10.0 \pm 3.19 \mathrm{mg}) . \mathbf{P O N V}$ occurred in 2 cases in group XE and 3 cases in group $\mathrm{K}$ and was not statisticallysignificant (table 2).

Table (2): analgesic requirements and incidence of post-operative complications among studied groups.

\begin{tabular}{|c|c|c|c|}
\hline & $\begin{array}{c}\text { Group } \\
\mathbf{X E} \\
\mathbf{N}=22\end{array}$ & $\begin{array}{c}\text { Group K } \\
\mathbf{N}=22\end{array}$ & test of significance \\
\hline $\begin{array}{l}\text { Time of first request of analgesia(h) } \\
(\text { mean } \pm \text { SD) }\end{array}$ & $2.14 \pm .94$ & $3.30 \pm 1.04$ & $\mathrm{t}=3.95, \mathrm{p}<0.001 *$ \\
\hline $\begin{array}{l}\text { Total postoperative morphine } \\
\text { consumption }(\mathrm{mg}) \text { in the first } 24 \mathrm{~h} \\
\text { post-operative } \\
(\text { mean } \pm \text { SD) }\end{array}$ & $10.0 \pm 3.19$ & $7.0 \pm 3.3$ & $\mathrm{t}=3.87, \mathrm{p}<0.001^{*}$ \\
\hline The incidence of PONV N (\%) & $2(9.1 \%)$ & $3(13.6 \%)$ & $\begin{array}{c}\text { FET } \\
p=1.0\end{array}$ \\
\hline
\end{tabular}




\section{DISCUSSION}

The research's central finding is that combining ketamine with xylocaine-epinephrine in local infiltration for rhinoplasty reduces the total quantity of morphine that was required in first 24-postoperative hours and increases the time until the first request for analgesiaoccurred. Local anesthetics combined with epinephrine are often used in a number of surgical procedures, including nose surgery, to guarantee sufficient exposure, extend the duration of the local anesthetic, and minimize adverse effects ${ }^{(7)}$.

The total amount of morphine required postoperatively was considerably less in group $\mathrm{K}$ $(7.0 \pm 3.3 \mathrm{mg})$ than in group XE $(10.0 \pm 3.19 \mathrm{mg})$, As a consequence, a statisticallysignificant reduction in groupK's VAS ratings at 1,2 hours postoperatively was notified. When comparing group $\mathrm{K}$ to group $\mathrm{XE}$, in group $\mathrm{K}$, the time gap between the procedure's conclusion and the first request for analgesia was much longer. $(3.30 \pm 1.04 \mathrm{~h}$ vs $2.14 \pm .94 \mathrm{~h})$.Similarly to our study, Jha et al. evaluated the preincisional use of $1 / 2$ milligram/kilogram ketamine and two $\mathrm{mg} / \mathrm{kg}$ bupivacaine with epinephrine in children undergoing palate surgery following general anesthesia and found that ketamine lowered postoperative pain ratings and analgesicneed significantly ${ }^{(8)}$.AlsoHonarmand et al. demonstrated that preincisional subcutaneous infiltration with ketamine $(1 / 2 \mathrm{mg} / \mathrm{kg})$ decreased postoperative pain scores, delayed time to 1 st rescue analgesia, and decreased after surgery analgesic requirements in patients undergoing appendectomy when its compared to a control group that received subcutaneous saline injections ${ }^{(9)}$.

In contrast to the findings of the present research,Lee $\boldsymbol{e t}$ al. found that adding $30 \mathrm{mg}$ ketamine to ropivacaine in the interscalene PPB had no effect on duration of the sensory deprivation or the postoperative analgesic need. ${ }^{(10)}$. This may be because the researchers used a lower dosage of ketamine than ours.Savafiet al.utilized subcutaneous ketamine infiltration prior to surgery to offer preemptive analgesia for patients having cholecystectomy. They found that two $\mathrm{mg} / \mathrm{kg}$ dosing of sc. infiltration of ketamine was associated with lower VAS score onlyat 15, 30 minutes postoperatively and same VAS score at 1, 2,3, 4, 8, 12, and 24 hours postoperatively when compared to $1 \mathrm{mg} / \mathrm{kg}$ dose of subcutaneous infiltration of ketamine ${ }^{(11)}$.Thus, in our research, we utilised a $1 \mathrm{mg}$ dosage.

Ketamine has a noncompetitive antagonistic effect on the NMDA receptor. The neurotransmitters both glutamate and aspartate are produced in response to painful stimuliand stick to NMDA and glutamate-type M receptors, respectively, contributing to the process of central sensitization and wind-up events, both of which contribute to the persistence of pain ${ }^{(12)}$.On primary afferent axons, Carlton et al. demonstrated the existence of NMDA and non-NMDA glutamate receptors, as well as an increase in their expression following inflammation ${ }^{(13)}$. Additionally, glutamate is released into peripheral tissue at a higher rate after injury and inflammation ${ }^{(14)}$. Thus, our findings are consistent with the notion that ketamine inhibits glutamate-induced activation of NMDA receptors on primary afferents in the skin, thus reducing peripheral nociceptive input to the spinal cord and central sensitization of the dorsal horn.

\section{CONCLUSION}

In conclusion, for rhinoplastywhen ketamine $(1 \mathrm{mg} / \mathrm{kg})$ is administered as adjuvant to xylocaine and epinephrine local infiltration, it offers efficient analgesia during the first twenty-fourhoursafter the surgery with no significant negative effects.

\section{Conflicts of Interest}

The authors state that this work is not subject to conflicts of interest.

\section{REFERENCES}

1. Goktas U, Isik D, Kati I, Atik B, Soyoral L (2011): Effects of lidocaine infiltration on cost of rhinoplasty made under general anesthesia.JCraniofacSurg.,22(6):21768.

2.Tomica B, Dinko B, Livija $\breve{S}$, Kata S̆ (2019): Impact of local infiltration anesthesia on postoperative pain management after arthroplasty in day care surgery. Acta Clin Croat., 58:62-66.

3. Ugur G,Daghan I (2011):Effects of Lidocaine Infiltration on Cost of Rhinoplasty Made Under General Anesthesia.TheJournal of craniofacial surgery,22(6):2176-8.

4. Steven Y,Nicholas H, Gary S(2013): Anaesthesiaand Intensive care $\mathrm{A}$ to $\mathrm{Z}, 4^{\text {th }}$ edition.https://www.abebooks.com/booksearch/kw/anaesthesia-and-intensive-care...

5.Taurá P, Fuster J, Blasi A, et al. (2003):Postoperative pain relief after hepatic resection in cirrhotic patients: the efficacy of a single small dose of ketamine plus morphine epidurally. Anesthesia \& Analgesia, 96.2: 475-480.

6. Mona B, Asmaa F (2018): Effects of adding dexamethasone or ketamine to bupivacaine for ultrasound-guided thoracic paravertebral block in patients undergoing modified radical mastectomy: A prospective randomized controlled study.Indian J Anaesth., 62(4): 285-291.

7. Mottura A (1995): The tumescent technique for face lifts: PlastReconstr Surg., 96: 231-232.

8. Jha A, Bhardwaj N, Yaddanapudi S, Sharma R, Mahajan J (2013): A randomized study of surgical site infiltration withbupivacaine or ketamine for pain relief in children followingcleft palate repair. PaediatrAnaesth., 23: 401-406.

9. Honarmand A, Safavi M, Karaky H (2012): Preincisional administration ofintravenous or subcutaneous infiltration of lowdose ketamine suppresses postoperative pain after appendectomy. J Pain Res., 5:1-6.

10. Lee I, Kim W, Kong Met al. (2002): No enhancement of sensory and motorblockade by ketamine added to ropivacaine interscalene brachial plexusblockade. Acta Anaesthesiol Scand., 46:821-826.

11. Safavi M, Honarmand A, Nematollahy $Z$ (2011): Preincisionalanalgesia with intravenous or subcutaneous infiltration ofketamine reduces postoperative pain in patients after open cholecystectomy: a randomized, double-blind, placebo controlled study. Pain Med., 12: 1418-1426.

12. Flores M, Castro A, Nascimento J(2012): Topical analgesics. Rev BrasAnestesiol., 62:244-252.

13. Carlton S, Coggeshall R(1999): Inflammation-induced changes in peripheral glutamate receptor populations. Brain Res., 820:6370.

14. Lawand N, McNearney T, Westlund $K$ (2000): Amino acidrelease into the knee joint: Key role in nociception andinflammation. Pain, 86:69-74. 